\title{
Dietary recommendation for Iron Deficiency Anemia in Persian Medicine
}

\author{
Review Article
}

\section{Somaye Fatali', Omid Sadeghpour ${ }^{2}$, Amir-Hosein Emami Jale Alias! ${ }^{4}$, Mitra Mehrabanis*}

\author{
1. Faculty of Traditional Medicine, Kerman University of Medical Sciences, Iran \\ 2. Research Institute for Islamic and Complementary Medicine, School of Persian Medicine, \\ Iran University of Medical Sciences, Tehran, IR Iran \\ 3. Department of Hematology/Oncology, Imam Khomeini Hospital, \\ Tehran University of Medical Sciences, Tehran, IR Iran \\ 4. Clinical Trial Research Center of Traditional Medicine, Shahed University, Tehran, IR Iran \\ 5. Herbal and Traditional Medicine Research Center, Kerman University of Medical Science, Kerman, IR Iran
}

\begin{abstract}
Background: Iron deficiency is the most common nutritional deficiency in the world. Iron deficiency anemia may be associated with various symptoms, and most patients are treated with oral supplements or infusion therapy. In recent years, importance of nutrition in the improvement of Iron deficiency anemia has been highlighted. Based on the Iranian Traditional Medicine, foods have major effects on prevention and treatment of diseases. Material and Methods: In this study Traditional Persian Medicine (TPM) books such as Canun of Avicenna, Kamil al-Sinaa alTibbiya and Makhzan al Advieh were assessed and the information about blood-producing foods and their effect on improving iron deficiency were investigated. Results: There are some foods, which can be effective in iron deficiency anemia. Some of these foods have animal origin such as eggs and meat and some have plant origin such as chickpeas, grapes and figs. Conclusion: According TPM, Nutritious foods and Blood humor-producing foods are the right options for iron supply. Also, these foods can help iron deficiency through various mechanisms alone or with medication.
\end{abstract}

Key Words: Anemia, Iron deficiency, Nutrient food, Persian Medicine.

\section{Introduction}

According to the World Health Organization (WHO), iron deficiency is the most common nutritional deficiency in the world $(1,2)$ and $30 \%$ of world population suffers from iron deficiency anemia (IDA) (3). Anemia is defined as a low hemoglobin concentration or red blood cell (RBC) mass compared with age-specific norms (4). The high prevalence of IDA in developing countries most often is concerned with nutritional deficiencies (5). Inadequate intake of dietary iron, chronic and inflammatory diseases, impaired iron absorption, and blood loss are the common causes of IDA (6). The most common symptom of IDA is fatigue; other signs or symptoms included palpitations, lethargy, feeling faint and becoming breathless easily, and ringing in the ears (tinnitus), dizziness, headache, coldness in your hands or feet, pale skin, gums and nail beds, as well as chest pain(7). IDA can lead to recurrent respiratory tract

\section{* Corresponding Author:}

\section{Mitra Mehrabani,}

Herbal and Traditional Medicine Research Center, Kerman University of Medical Science, Kerman, IR Iran.

Email id - mmehrabani@gmail.com infections and gastroenteritis(8) Visceral Obesity(9) pagophagia (ice craving) and can lead to gingival disease (10). In IDA Red cell indices will also change gradually becoming microcytic and hypochromic (10).

Most patients are treated with oral supplements or infusion therapy. In recent years, importance of nutrition in the improvement of IDA has been highlighted $(5,11,12)$. An average diet can provide $10-20 \mathrm{mg}$ of iron per day, $10-15 \%$ of which is absorbed in healthy adults; nonetheless, absorption is dependent on the body's iron storage (6). Based on the Traditional Persian Medicine (TPM), foods have major effects on the prevention and treatment of diseases and provide the required compounds for humor production. Razes said: "Do not go for medication as long as you can treat it with food"(13). Therefore, this review will try to highlight nutritional recommendations, which can help to prevent or treat IDA.

\section{Methods}

This study was performed based on the TPM approaches. First, the issue of blood-producing food in TPM sources including: Al-Qanun fi al-Tibb(14), AlHawi fi al-Tibb (13), Kamil al-Sinaa al-Tibbiya (15), Tebb-e-Akbari (16), Makhzan al Advieh (17), Exir-e Azam (18) and Kholasatol-Hikmah (19) was studied. These materials were then searched in Medline, Science 
direct, and SID. All the information about bloodproducing foods was gathered and classified. Finally, the data were evaluated.

\section{Results}

According TPM, food compounds, which are digested in the gastrointestinal system, spread among body organs or transform into energy in the body (17). When food enters the stomach, it is converted into a substance, called chylos. Then, it moves towards the liver through the mesenteric vein and converts to metabolites, known as humor. Humor is distributed throughout the body via vessels and is converted to the organs after some processing $(20,21)$.

Liver produces 4 humors including blood, phlegm, yellow bile, and black bile. Blood humor, as the predominant humor, is an essential part of nutrition, growth and replaces the consumed energy in the, body(14, 15, 18). There are some foods, which can produce more blood humor by the liver after digestion $(16,18)$. These foods are categorized into Table 1 . Energy, protein, and iron content of blood-producing foods in 100 gram of each medicinal food were showed in Table $1(22,23)$.

In TPM, some foods (Kathir-Al-Ghaza) have more absorption in the body, in other words, they produce humors more than other food types $(24,25)$. And also there are some foods which produce Blood humor (Movalled-E-Dam). These foods lead to the production of more blood humor in the body. Of course, not all of these foods have high levels of nutrient or iron $(24,26)$.

Foods which are on top of the list, includes egg, wheat, raisin, and barely, are highly nutritive and contribute to blood production. Conversely, some foods with low energy level, low protein content, and low iron level (e.g. watermelon, pomegranate, jujube, and shrimp) are at the bottom of the list.

In TPM, in addition to the type of food, the dishes in which the food is cooked also affects our health (14). Cooking in iron pots can improve iron deficiency anemia $(27,28)$. Old folks told us to place iron nails or any piece of iron materials to a clay or ceramic pot when we cook food $(27,28)$. As shown in one study, children whose food was cooked in iron pots had a lower rate of anemia and increased growth than children who had cooked in aluminum pots. They concluded that providing iron cookware to families in less developed countries may be a useful way to prevent iron deficiency anemia (27).

\section{Discussion}

According to TPM, blood humor is used to meet an individual's daily needs and maintain metabolic reactions, growth and development (19). Production of good blood humor is attributed to the digestion of healthy foods, because, despite the proper function of the gastrointestinal system, humor cannot be produced adequately if nutrients have a poor quality. Production of good blood humor can lead to an increase in blood used by the organs. Foods with this criterion have a high nutritional value (Kathir-Al-Ghaza) and bloodproducing food (Movalled-E-Dam). According to
Table 1, these foods can help produce blood humor. Nutritional foods have high energy and protein levels for blood humor production. Therefore, these foods can be a proper choice for growth, development and improvement of body's metabolic system. On the other hand, some nutritional sources, such as watermelon and pomegranate, have low iron content, they show hepatoprotective activities. Additionally, they have antioxidant and anti-inflammatory effects in the liver (29).

As mentioned above, liver plays a fundamental role in the production of blood humor. It also has a major contribution to the absorption and storage of iron, production of hemoglobin, and function of the bone marrow. The liver adjusts iron absorption from the gastrointestinal tract by hepcidin and apo-transferrin. Overall, $30 \%$ of ferritin storage and $15 \%$ of hemoglobin production occur in the liver $(30,31)$. Therefore, the consumption of these foods prepare the raw materials needed for the production of blood humors and, also, help the liver to absorb more iron extracted from the gastrointestinal tract and also store more iron in the liver.

In TPM, the foods are categorized according to the duration of digestion and the quality of the produced blood. Some foods, such as egg and bird meat, are suitable for the recovery of patients, as digestion of these foods is simple and can ameliorate weakness. Therefore, they can be used when the patient experiences weakness and gastrointestinal disorders. Some foods (e.g. beef and meat of some birds), which produce viscous blood and have a long digestion time, are suitable for athletes and people with physical activity.

On the contrary, cheese with moderate iron content is not a blood-producing food, as it has no hepatoprotective activity and its scarce overuse can lead to liver dysfunction (17). On the other hand, some foods with a high nutritional value show blood-producing activities and have a moderate to high iron level. These foods, such as egg, meat, barely, and raisin, can be used for people with more nutritional needs (e.g., pregnant and breastfeeding women).

Recent studies have also shown the efficacy of these foods on IDA. The raisin is a source of vitamin C, B-12, and iron, which has an important role in treatment of anemia by increase the numbers of RBCs (32). Another study showed that the combination of jaggery with raisins as a better natural dietary supplement to overcome IDA without prominent side effects as observed with oral and parenteral iron preparations (33). About the grape molasses, a study found that in non-anemic individuals, iron absorption from grape molasses was comparable to ferrous sulfate. Therefore, grape molasses is an effective source of iron in preventing iron deficiency anemia (34) Investigating the effects of chickpea on anemia, animal studies in female rats showed that chickpea seed is an effective source of iron supplementation for IDA in mice and can be developed as a functional product to overcome malnutrition-induced iron deficiency (35).

And also clinical study demonstrated that egg consumption plays an essential role in protecting the 
health of the body and good source of iron and frequent consumption of egg results in improvements in plasma iron and transferrin saturation (36). Studies indicate egg white protein was useful for recovery from IDA (37). Pomegranates are also effective in improving anemia as the results of a clinical study demonstrate that pomegranate juice consumption of $500 \mathrm{ml} /$ day for two weeks increased significant the RBC count, hemoglobin concentration and hematocrit in healthy individuals. (38). The present study showed that in patients with IDA, nutritional foods, in combination with iron supplements, can be used for treatment. Generally, nutritional foods can be used to treat IDA in 2 ways. First, some of these foods have a high iron level, and second, they increase iron absorption from the gastrointestinal tract and improve iron storage because of the hepatoprotective effects.

\section{Conclusion}

Nutritional recommendations of TPM in the prevention and treatment of Iron deficiency anemia can have a significant impact. Clinical studies are suggested to prove the effects of these foods in iron deficiency anemia subjects.

\section{Conflict of interest}

The authors are having no conflict of interest.

\section{Abbreviations}

IDA: iron deficiency anemia, TPM: Traditional Persian Medicine, RBC: red blood cell, WHO: World Health Organization

\section{References}

1. Schroth RJ, Levi J, Kliewer E, Friel J, Moffatt ME. Association between iron status, iron deficiency anaemia, and severe early childhood caries: a casecontrol study. BMC Pediatrics. 2013;13:22:1-7.

2. McLean E, Cogswell M, Egli I, Wojdyla D, de Benoist B. Worldwide prevalence of anaemia, WHO Vitamin and Mineral Nutrition Information System, 1993-2005. Public health nutrition. 2009 Apr;12(4):444-54.

3. Chaturvedi D, Chaudhuri PK, Chaudhary AK. Study of correlation between dietary habits and anemia among adolescent girls in Ranchi and its surronding area. International Journal of Contemporary Pediatrics. 2017;4(4):1165-8.

4. Pettei MJ, Weinstein T, Eden A. Screening for Iron Deficiency. Pediatrics. 2016 Jun;137(6).

5. Prentice AM, Mendoza YA, Pereira D, Cerami C, Wegmuller R, Constable A, et al. Dietary strategies for improving iron status: balancing safety and efficacy. Nutrition reviews. 2016;75(1):49-60.

6. Santiago P. Ferrous versus ferric oral iron formulations for the treatment of iron deficiency: a clinical overview. TheScientificWorldJournal. 2012;846824.

7. Soundarya N, Suganthi P. A review on anaemia types, causes, symptoms and their treatments. Journal of science and technology investigation 2017;1(1).
8. Jayaweera JAAS, Reyes M, Joseph A. Childhood iron deficiency anemia leads to recurrent respiratory tract infections and gastroenteritis. Scientific reports. 2019;9(1):1-8.

9. Yook J-S, Zhou M, Jaekwon L, Chung S. Iron Deficiency Anemia (IDA) Promotes Visceral Obesity Due to Defective Adipose Tissue Browning (OR09-07-19). Oxford University Press; 2019.

10.Auerbach M, Adamson JW. How we diagnose and treat iron deficiency anemia. American journal of hematology. 2016;91(1):31-8.

11.Cui Y, Wu Q, Zhou Y. Iron-Refractory Iron Deficiency Anemia: New Molecular Mechanisms. Kidney Int 2009; 76(11): 1137-41.

12.Mirmiran P, Golzarand M, Serra-Majem L, Azizi F. Iron, iodine and vitamin a in the middle East; a systematic review of deficiency and food fortification. Iranian journal of public health. 2012;41(8):8.

13.Rhazes M-Z. Al-Havi (Liber Continent). Tehran: Shahid Beheshti University of Medical science 2016.

14.Avicenna M. Al Qanun Fi Al-Tibb(Arabic) beirut: Alaalami library; 2005.

15.Ahvazi AIA. Kamel-o-Sanaah. qom: institute of Revival of Natural Medicine; 2008.

16.Arzani ma. Tebb-e-Akbari (Akbari Medicine). Tehran: choogan; 2016.

17.Aghili-Khorasani S-M-H. Makhzan al Advieh: Iranian teb; 2017.

18.Azam-khan M. Exir-e- Azam. Tehran university of medical science: Almaee; 2014.

19.SMH A-K. kholasatol hikmat fe teb. Qom: esmailian; 2006.

20. Yarjou S, Sadeghpour O, Nazem E, Emami AH. Liver function and anemia pathogenesis in Iranian traditional medicine. Iranian Red Crescent medical journal. 2015 Jan;17(1):e17099.

21.Alizadeh M, Khadem E, Aliasl J. Diagnosis Protocol of Stomach Distemperament for Clinical Practice in Iranian Traditional Medicine: A Narrative Review. Iranian journal of public health. 2017 Jul;46(7):877-81.

22.Kloots W, Op den Kamp D, Abrahamse L. In vitro iron availability from iron-fortified whole-grain wheat flour. Journal of agricultural and food chemistry. 2004 Dec 29;52(26):8132-6.

23. Dewey KG. Increasing iron intake of children through complementary foods. Food and nutrition bulletin. 2007 Dec;28(4 Suppl):S595-609.

24.Shirazi M. Kefayeh Mansoori. Tehran: Iran University of Medical science; 2003.

25.Liu J, Sun B, Yin H, Liu S. Hepcidin: A Promising Therapeutic Target for Iron Disorders: A Systematic Review. Medicine. 2016 Apr;95(14):e3150.

26.Miller JL. Iron deficiency anemia: a common and curable disease. Cold Spring Harbor perspectives in medicine. $2013 \mathrm{Jul}$ 01;3(7).

27.Adish AA, Esrey SA, Gyorkos TW, Jean-Baptiste J, Rojhani A. Effect of consumption of food cooked in iron pots on iron status and growth of young children: a randomised trial. The lancet. 1999;353(9154):712-6. 
28.Geerligs PD, Brabin BJ, Omari AA. Food prepared in iron cooking pots as an intervention for reducing iron deficiency anaemia in developing countries: a systematic review. Journal of human nutrition and dietetics : the official journal of the British Dietetic Association. 2003 Aug; 16(4):275-81.

29.Bhandari PR. Pomegranate (Punica granatum L). Ancient seeds for modern cure? Review of potential therapeutic applications. The International Journal of Nutrition, Pharmacology, Neurological Diseases 2012;2(3):171-84.

30.Hoffbrand V, Moss P. Essential Haematology, Includes Desktop Edition: Wiley; 2011.

31.Bhghavan nv. medical biochemistry. Printed in China: Lippincott Williams \& Wilkins; 2011.

32.Jouda J, El-Haboby B, Jasim W, Ahmed E. The Effect of Iraqi Yellow Raisin on the Brain regions and the Blood Cells Count. Advances in Environmental Biology. 2016;10(8):112-8.

33.Sakthibalan M, Sarumathi E, Mangaiarkkarasi A, Meher BR. Evaluation of efficacy of jaggery and raisins as supplements in iron deficiency anemia among medical undergraduate students in South India. National Journal of Physiology, Pharmacy and Pharmacology. 2018;8(10):1432-6.
34.Aslan Y, Erduran E, Mocan H, Gedik Y, Okten A, Soylu $\mathrm{H}$, et al. Absorption of iron from grapemolasses and ferrous sulfate: a comparative study in normal subjects and subjects with iron deficiency anemia. The Turkish journal of pediatrics. 1997;39(4):465-71.

35.Huang Y, Xin M, Li Q, Luo X, Wang X, Zou X, et al. Chickpea seeds ferritin as a potential source in the treatment of iron deficiency anemia. J Food Nutr Res. 2014;2:876-9.

36. Ayele BH, Getachew A, Irenso AA, Abate D, Tesfa T. Anemia and Its Associated Factors among Haramaya and Dire Dawa University Students, Eastern Ethiopia. East African Journal of Health and Biomedical Sciences. 2019;3(2):1-12.

37.Kobayashi Y, Wakasugi E, Yasui R, Kuwahata M, Kido Y. Egg yolk protein delays recovery while ovalbumin is useful in recovery from iron deficiency anemia. Nutrients. 2015;7(6):4792-803.

38.Manthou E, Georgakouli K, Deli CK, Sotiropoulos A, Fatouros IG, Kouretas D, et al. Effect of pomegranate juice consumption on biochemical parameters and complete blood count. Experimental and therapeutic medicine. 2017;14(2):1756-62.

Table 1: Foods improving Anemia Energy, protein, and iron content of blood-producing foods in 100 gram of each medicinal food

\begin{tabular}{|c|c|c|c|c|c|c|c|}
\hline $\begin{array}{c}\begin{array}{c}\text { Common } \\
\text { name }\end{array} \\
\end{array}$ & Scientific name & $\begin{array}{c}\text { Traditional } \\
\text { name }\end{array}$ & $\begin{array}{c}\text { Movalled- } \\
\text { E-Dam }\end{array}$ & $\begin{array}{c}\text { Kathir-Al- } \\
\text { ghaza }\end{array}$ & $\begin{array}{c}\text { Energy (K } \\
\text { cal) }\end{array}$ & $\begin{array}{c}\begin{array}{c}\text { Protein } \\
\text { (g) }\end{array} \\
\end{array}$ & $\begin{array}{l}\text { Iron } \\
(\mathrm{mg})\end{array}$ \\
\hline Wheat & Triticum aestivum $L$. & Hentah & + & + & 268 & 10.8 & 3.4 \\
\hline Egg, yolk & --- & Bayz & + & + & 322 & 15.8 & 2.7 \\
\hline Raisin & Vitis vinifera $L$. & Zabeeb & + & + & 297 & 2.5 & 2.59 \\
\hline Barley & Hordeum valgare $L$. & Shaeer & + & + & 352 & 9.9 & 2.52 \\
\hline Pea & Cicer arietinum $L$. & Hemmas & + & + & 124 & 8.8 & 2.2 \\
\hline Egg, whole & --- & Bayz & + & + & 143 & 12.5 & 1.75 \\
\hline Meat & --- & Lahm & + & + & 277 & 12.3 & 1.6 \\
\hline Pear & Pyrus commonis L. & Amrood & - & + & 57 & 0.3 & 0.18 \\
\hline Grape, seeded & Vitis vinifera $L$. & Enab & + & + & 69 & 0.7 & 0.36 \\
\hline Fig & Ficus carcica $L$. & Teen & + & + & 74 & 0.75 & 0.37 \\
\hline Milk & --- & Laban & - & + & 108 & 5.9 & 0.1 \\
\hline Cheese & --- & Jobon & _- & + & 264 & 14.2 & 0.65 \\
\hline Date & $\begin{array}{c}\text { Phoenix dactylifera } \\
\text { L. }\end{array}$ & Tamr & + & + & 304 & 2.17 & 0.78 \\
\hline Pomegranate & Punica granatum L. & Romman & + & - & 83 & 1.6 & 0.3 \\
\hline Watermelon & $\begin{array}{l}\text { Citrullus vulgaris } \\
\text { Schard } \\
\end{array}$ & Bettikh & + & - & 30.2 & 0.6 & 0.24 \\
\hline Jujube & Zizyphus vulgaris L. & $A n n a b$ & + & - & 79 & 1.2 & 0.48 \\
\hline Shrimp & Penaeidae & Rubian & + & - & 85 & 20.1 & 0.52 \\
\hline
\end{tabular}

